\title{
Improved Oxidation of Naringenin to Carthamidin and Isocarthamidin by Rhodotorula marina
}

\author{
Anna Madej • Jarosław Popłoński • Ewa Huszcza
}

Received: 9 May 2013 / Accepted: 10 February 2014 /

Published online: 11 March 2014

(C) The Author(s) 2014. This article is published with open access at Springerlink.com

\begin{abstract}
A novel single-step microbial transformation process for the efficient production of carthamidin and isocarthamidin from naringenin by yeast Rhodotorula marina in an aerated bioreactor was described. The biotransformation led to the total product concentration of $233 \mathrm{mg} / \mathrm{l}$. The highest conversion efficiency observed for carthamidin was $0.31 \mathrm{mg} / \mathrm{mg}$ of naringenin and for isocarthamidin $0.47 \mathrm{mg} / \mathrm{mg}$ of naringenin.
\end{abstract}

Keywords Naringenin Carthamidin - Isocarthamidin - Biotransformation Rhodotorula marina

\section{Introduction}

Flavonoids are polyphenolic compounds of plant origin that are important constituents of the human diet. They have been reported to possess a wide spectrum of health-promoting properties, including antibacterial, antiviral, estrogenic, anti-obesity, and anticancer activities, which are useful in the treatment of several human pathologies [1].

Naringenin (Fig. 1) is one of the most abundant flavonoids found in grapes, tomatoes, and citrus fruits. This flavanone has gained increasing interest in recent years because of its wide range of biological activity, including antioxidant [2], anti-inflammatory [3], antimicrobial $[4,5]$, antiviral [6], antimutagenic [7], antiestrogenic [8], antiatherogenic [9], hepatoprotective $[10,11]$, nephroprotective [12], and anticancer $[13,14]$ action. Positive effects of naringenin on lipid metabolism $[15,16]$ and plasma glucose levels [16-19] have also been reported.

Since naringenin is a compound isolated from the agro-residue, it is relatively inexpensive. Not only does it serve as an excellent and frequently employed model flavonoid but also it is a leading substance for the preparation of new biologically active derivatives. For this purpose both chemical and biotransformation methods have been used. Chemical modifications involved acylation [20] and $O$-alkylation $[20,21]$ while biotransformations using microorganisms, plant cultured cells, and pure enzymes led to glycosylation [22], $O$-alkylation [23], acylation [24], halogenation [25], sulfation [26, 27], C-C coupling [28], and hydroxylation [29-32].

A. Madej · J. Popłoński $\cdot$ E. Huszcza $(凹)$

Department of Chemistry, Wrocław University of Environmental and Life Sciences, Norwida 25,

50-375 Wrocław, Poland

e-mail: ewa.huszcza@up.wroc.pl 


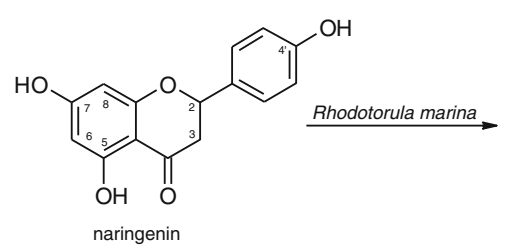<smiles>O=C1CC(c2ccc(O)cc2)Oc2cc(O)c(O)c(O)c21</smiles>

Fig. 1 Transformation of naringenin by Rhodotorula marina

The last of these modifications, conducted by the fungi of the genus Aspergillus, afforded carthamidin (6-hydroxynaringenin) and isocarthamidin (8-hydroxynaringenin). These metabolites exhibited much stronger antioxidant activity than both naringenin and its glycoside naringin [29]. The activity of the isocarthamidin is comparable to that of $\alpha$-tocopherol, whereas carthamidin is slightly less active. Kim et al. [33] suggested that these compounds obtained by fermentation of Dangyuja (Citrus grandis Osbeck) extract increased also the antidiabetic activity of the raw material used. A novel antidiabetic agent which contains carthamidine and/or isocarthamidin as active ingredients was also patented [34].

Recently, 8-hydroxynaringenin has been identified as a suicide substrate of mushroom tyrosinase [35], which greatly expands the range of its possible applications. Tyrosinase is a monooxygenase known to be the key enzyme in melanin biosynthesis, by catalyzing the oxidation of phenol to $O$-chinone, observed in the early stage of various browning phenomena in nature $[36,37]$. Tyrosinase inhibitors can therefore be useful for the control of enzymatic browning during fruit and vegetable pulp manufacturing [38], for the treatment of some dermatological disorders associated with melanin hyperpigmentation [39] and neurodegeneration [40, 41], for whitening and depigmentation in cosmetics [42, 43], and for insect control [44].

For the above reasons and because of low content of carthamidin and isocarthamidin in plant material [45-48], it is desirable to develop effective methods of obtaining carthamidin and isocarthamidin from naringenin. Biotransformation is a method that allows for regioselective hydroxylation of the substrate and, at the same time, preserves the status of the products as "natural compounds." Therefore, it is particularly useful in this respect.

This paper describes biotransformation leading to carthamidin and isocarthamidin, carried out on a preparative scale and using yeast as a biocatalyst.

\section{Materials and Methods}

Microorganism

The yeast strain Rhodotorula marina AM77 was purchased from Institute of Biology and Botany of the Wrocław Medical University, Poland.

Substrate

Naringenin was purchased from Sigma-Aldrich.

Products

Carthamidin $\left(5,6,7,4^{\prime}\right.$ - tetrahydroxyflavanone) ${ }^{1} \mathrm{H}$ NMR $\left(600 \mathrm{MHz}, \mathrm{DMSO}-d_{6}\right) \delta$ (ppm): 2.65 (dd, $1 \mathrm{H}, J=17.1 ; 3.0 \mathrm{~Hz}, \mathrm{H}-3 \mathrm{eq}) ; 3.22$ (dd, 1H, $J=17.1 ; 12.3 \mathrm{~Hz}, \mathrm{H}-3 \mathrm{ax}$ ); 5.36 (dd, 1H, $J=12.8 ; 2.9 \mathrm{~Hz}, \mathrm{H}-2) ; 5.94$ (s, 1H, H-8); 6.79 (d, 2H, J=8.5 Hz, H-3', 5'); 7.31 (d, 2H, 
$\left.J=8.6 \mathrm{~Hz}, \mathrm{H}-2^{\prime}, 6^{\prime}\right) ; 8.11$ (s, 1H, 7-OH); 9.57 (s, 1H, 4'-OH); 10.42 (s, 1H, 6-OH); 11.98 (s, 1H, 5-OH). ${ }^{13} \mathrm{C}$ NMR (DMSO- $\left.d_{6}\right) \delta$ (ppm): 42.32 (C-3); 78.50 (C-2); 94.73 (C-8); 101.71 (C-10); 115.16 (C-3', 5'); 126.32 (C-6); 128.30 (C-2', 6'); 129.19 (C-1'); 150.19 (C-9); 155.27 (C-5); 155.77 (C-7); 157.65 (C-4'); 196.66 (C-4). HR ESI-MS m/z: 287.0520 [M-H] ${ }^{-}$(calcd for $\left.\mathrm{C}_{15} \mathrm{H}_{12} \mathrm{O}_{6}-\mathrm{H}, 287.0556\right)$; UV (MeOH) $\lambda_{\max } 292.7 \mathrm{~nm}$.

Isocarthamidim $\left(5,7,8,4\right.$ '- tetrahydroxyflavanone) ${ }^{1} \mathrm{H}$ NMR $\left(600 \mathrm{MHz}, \mathrm{DMSO}-d_{6}\right) \delta$ (ppm): 2.71 (dd, 1H, $J=17.1 ; 3.1 \mathrm{~Hz}, \mathrm{H}-3 \mathrm{eq}) ; 3.22$ (dd, 1H, $J=17.1 ; 12.3 \mathrm{~Hz}, \mathrm{H}-3 \mathrm{ax}) ; 5.42$ (dd, 1H, $J=12.3 ; 2.9$ Hz, H-2); 5.93 (s, 1H, H-6); 6.79 (d, 2H, J=8.5 Hz, H-3', 5'); 7.35 (d, 2H, $\left.J=8.5 \mathrm{~Hz}, \mathrm{H}-2^{\prime}, 6^{\prime}\right) ; 8.11$ (s, 1H, 7-OH); 9.57 (s, 1H, 4'-OH); 10.42 (s, 1H, 8-OH); 11.75 $(\mathrm{s}, 1 \mathrm{H}, 5-\mathrm{OH}) .{ }^{13} \mathrm{C}$ NMR (DMSO- $\left.d_{6}\right) \delta$ (ppm): 42.28 (C-3); 78.50 (C-2); 95.44 (C-6); 101.71 (C-10); 115.12 (C-3',5'); 125.61 (C-8); 128.40 (C-2', 6'); 129.19 (C-1'); 149.41 (C-9); 156.51 (C-5); 155.81 (C-7); 157.65 (C-4'); 196.62 (C-4). HR ESI-MS m/z: 287.05200 [M-H] (calcd for $\left.\mathrm{C}_{15} \mathrm{H}_{12} \mathrm{O}_{6}-\mathrm{H}, 287.0556\right)$; UV (MeOH) $\lambda_{\max } 293.9 \mathrm{~nm}$.

\section{Biotransformation Procedure}

The growth medium for inoculum preparation and for biotransformation process (Sabouraud medium) contained $3 \%$ glucose and $1 \%$ bacto peptone (Difco). A seed culture was grown in a six 300-ml flasks (each containing $50 \mathrm{ml}$ of the growth medium) on a shaker at $28^{\circ} \mathrm{C}$ for 2 days to obtain the cell dry weight of $c a .7 \mathrm{~g} / \mathrm{L}$. The inoculum in amount of $300 \mathrm{ml}$ was introduced into a 5-1 fermenter (Biostat B Plus, Sartorius, Germany), containing 1.71 of the medium. After $24 \mathrm{~h}$ of cultivation at $28{ }^{\circ} \mathrm{C}, 600 \mathrm{mg}$ of naringenin dissolved in $15 \mathrm{ml}$ of methanol was added. The aeration rate was fixed at $0.6 \mathrm{v} / \mathrm{v} / \mathrm{m}$. The stirrer speed was adjusted to $600 \mathrm{rpm}$, and the dissolved oxygen concentration was maintained at $45 \pm 5 \%$ saturation. The progress of naringenin conversion was monitored by thin layer chromatography (TLC) and high-performance liquid chromatography (HPLC). This procedure was repeated three times. Substrate control sample consisted of naringenin and a sterile growth medium incubated without a microorganism.

\section{Sample Preparation}

Five milliliters of the culture medium was acidified with $1 \mathrm{M} \mathrm{HCl}$ to $\mathrm{pH} 4$ and extracted three times with $7.5 \mathrm{ml}$ of ethyl acetate. The combined extracts were evaporated and the residue dissolved in methanol and analyzed by TLC and HPLC.

\section{Products Isolation and Analysis}

TLC was carried out on Merck silica gel $60 \mathrm{~F}_{254}(0.2 \mathrm{~mm}$ thick) plates. Compounds were

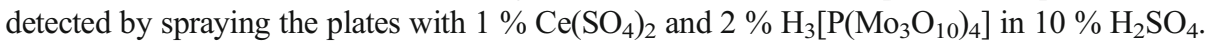
HPLC was performed on a Waters 2695 Aliance instrument with a photodiode array detector Waters 2996 (detection at 290-nm wavelength) using the analytical HPLC column Agilent ZORBAX Eclipse XDB $5 \mu \mathrm{m}(46 \times 250 \mathrm{~mm})$. Separation conditions: flow rate of $0.8 \mathrm{ml} / \mathrm{min}$; mobile phase A: acetonitrile; mobile phase B: $0.1 \%$ acetic acid in water. Chromatographic separation was achieved using the gradient elution: linear gradient of A from 25 to $38 \%$ over $10 \mathrm{~min}$, isocratic elution of A $38 \%$ for $18 \mathrm{~min}$, linear gradient of A from 38 to $25 \%$ over $2 \mathrm{~min}$, and isocratic elution of A $25 \%$ for 6 min.

When the biotransformation was complete, the culture was acidified with $1 \mathrm{M} \mathrm{HCl}$ to $\mathrm{pH} 4$ and extracted three times with $0.5 \mathrm{~L}$ of ethyl acetate. The combined organic phases were evaporated and the products separated by column chromatography on Sephadex LH-20 gel (Pharmacia) using chloroform/methanol $(8: 2 v / v)$ as eluent. Quantitative analysis of the ethyl 
acetate extract of the biotransformation mixture was performed by means of HPLC, using calibration curves for the substrate and for all the isolated products.

Nuclear magnetic resonance (NMR) spectra $\left({ }^{1} \mathrm{H}\right.$ NMR, ${ }^{13} \mathrm{C}$ NMR, DEPT $135^{\circ},{ }^{1} \mathrm{H}-{ }^{1} \mathrm{H}$ NMR (COSY), and ${ }^{1} \mathrm{H}-{ }^{13} \mathrm{C}$ NMR (HMQC)) were recorded on a MHz DRX Bruker Avance ${ }^{\mathrm{TM}} 600$ $(600 \mathrm{MHz})$ instrument in DMSO- $d_{6}$ (Sigma-Aldrich). UV spectra were run on a Spectrofotometer Cintra 303, GBC, in methanol (Merck). Negative-ion electrospray ionization tandem mass spectrometry (ESI-MS) spectra were measured on a Bruker micrOTOF-Q spectrometer.

Free Radical-Scavenging Activity Assay

Free radical-scavenging activity was measured essentially by the method proposed by Sharma and Bhat [49] using 1,1-diphenyl-2-picrylhydrazyl (DPPH, Sigma-Aldrich). Briefly, $1 \mathrm{ml}$ of $0.5 \mathrm{mM}$ methanolic solution of DPPH radical was added to $2 \mathrm{ml}$ of methanol and $2 \mathrm{ml}$ of methanolic test samples of different concentrations. Final concentration of DPPH in each sample was $100 \mu \mathrm{M}$ $(0.5 \mu \mathrm{mol})$. The solvents and other chemicals were of analytical grade. The mixtures were shaken vigorously and left to stand for $30 \mathrm{~min}$ at room temperature in the dark. The absorbance at $517 \mathrm{~nm}$ by DPPH was measured by UV-vis spectrophotometry. Naringenin was used as a control.

The percentage of inhibition of the DPPH radical by the samples was calculated as follows:

$$
\text { Inhibition }[\%]=100 \times\left(\mathrm{ABS}_{t=0}-\mathrm{ABS}_{t=30}\right) / \mathrm{ABS}_{t=0},
$$

where $\mathrm{ABS}_{t=0}$ was the absorbance of $\mathrm{DPPH}$ at time 0 and $\mathrm{ABS}_{t=30}$ was the absorbance of $\mathrm{DPPH}$ after $30 \mathrm{~min}$ of incubation. Sample concentration providing $50 \%$ of inhibition $\left(\mathrm{IC}_{50}\right)$ was calculated from the graph plotting inhibition percentage against compound concentration in a sample. All measurements were made in triplicates. One-way analysis of variance (ANOVA) was performed with SPSS. The differences were considered significant at $p<0.05$ using the post hoc evaluation with Fisher's least significant difference test.

\section{Results and Discussion}

Recently, we reported the ability of the yeast Rhodoorula marina to transform naringenin into polyhydroxylated products: carthamidin and isocarthamidin [31]. In those studies, the biotransformation was carried out in Erlenmeyer flasks, with the maximum initial concentration

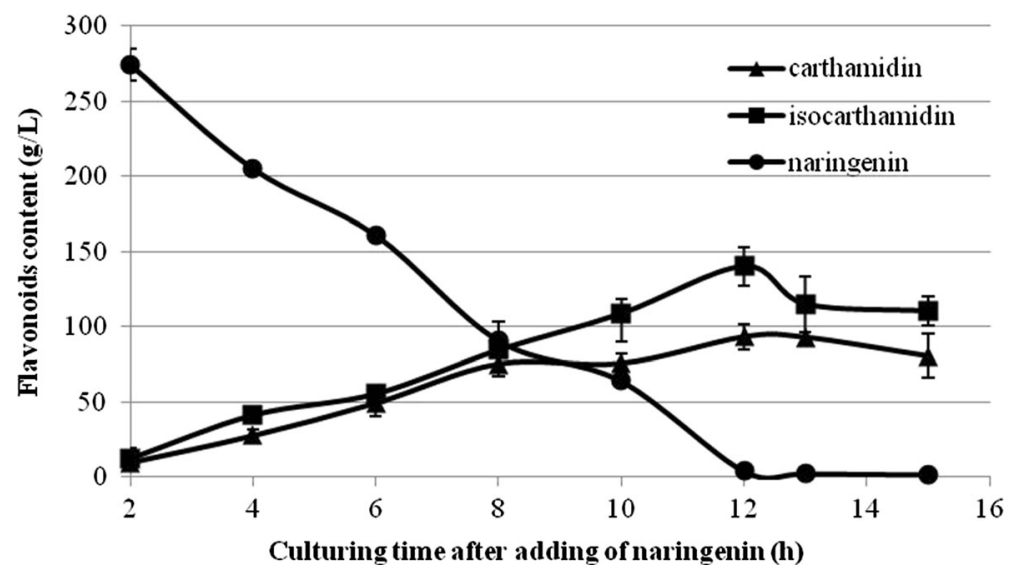

Fig. 2 The course of naringenin transformation in the Rhodotorula marina culture (determined by HPLC) 


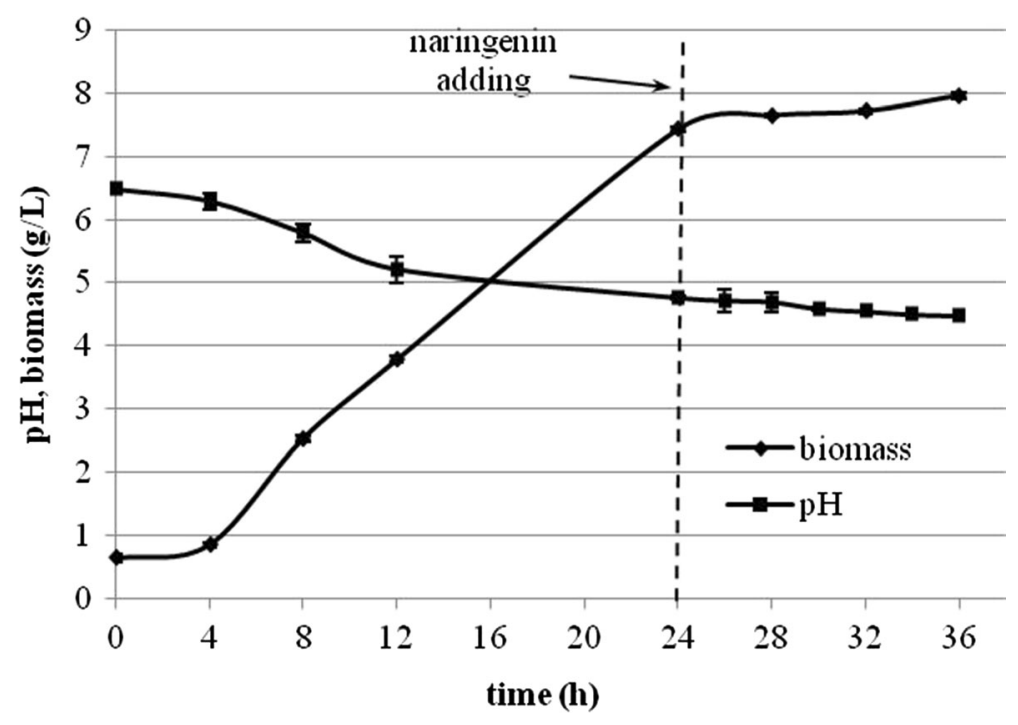

Fig. 3 Growth curve of Rhodotorula marina on 2-1 scale in a fermenter

of naringenin of $300 \mathrm{mg} / \mathrm{l}$. The present research focuses on performing this reaction in a larger scale, using a bioreactor.

The products of naringenin biotransformation - carthamidin and isocarthamidin - were unambiguously identified by spectroscopic methods (NMR, UV, and HR ESI-MS).

Figure 2 shows the time course of bioconversion of naringenin run in a 2.0-1 batch culture. To a 24-h-old culture of the dry biomass concentration of $7.4 \mathrm{~g} / \mathrm{l}$ (Fig. 3), $600 \mathrm{mg}$ of the substrate $(300 \mathrm{mg} / \mathrm{l})$ was added. Both products appeared simultaneously and accumulated in the reaction mixture at highest rate over $12 \mathrm{~h}$.

Maximum conversion efficiency of carthamidin was $0.31 \mathrm{mg} / \mathrm{mg}$ of naringenin and that of isocarthamidin was $0.47 \mathrm{mg} / \mathrm{mg}$ of naringenin. At this stage of the biotransformation, the total

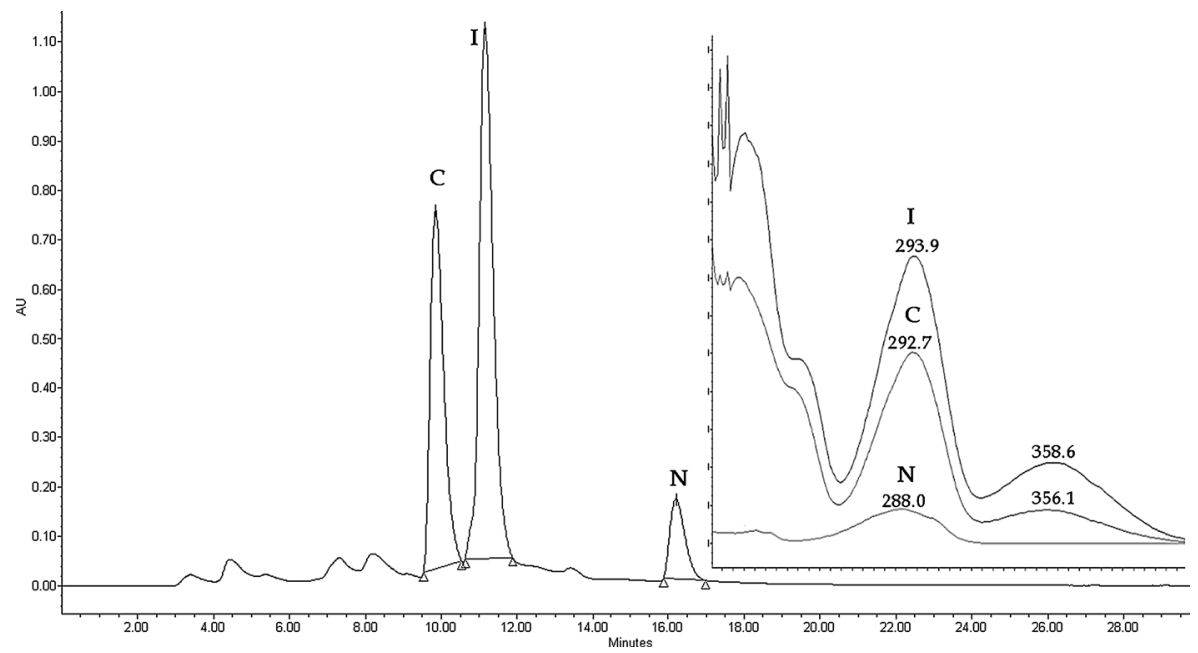

Fig. 4 HPLC elution profile of extract of 12-h biotransformation mixture; $N$ naringenin, $C$ carthamidin, $I$ isocarthamidin 
concentration of the flavonoids in the bioreactor determined by HPLC (Fig. 4) was found to be $237.3 \mathrm{mg} / 1$ (93.3 mg/l for carthamidin, $140.0 \mathrm{mg} / 1$ for isocarthamidin, and $4.0 \mathrm{mg} / \mathrm{l}$ for naringenin). The specific production rate for the mixture of carthamidin and isocarthamidin reached the value of $0.065 \mathrm{~g} / \mathrm{gl}$ and the maximal yield of $0.399 \mathrm{~g} / \mathrm{g}$. Both microbial growth time and biotransformation time were considerably shorter compared to the cultures cultivated in shaken Erlenmeyer flasks. In a 24-h-old culture, we obtained the cell dry biomass of $7.43 \mathrm{~g} / \mathrm{L}$, whereas such a value was observed earlier for a 41-h-old culture [31]. Biotransformation time was also much shorter, as after $12 \mathrm{~h}$ in the bioreactor, there was no more naringenin observed, while in Erlenmeyer flasks, it was present in amount of $83 \%$ of the flavonoid mixture.

In the laboratory scale studies conducted by Xu et al. (2012) using Aspergillus niger as a biocatalyst, similar conversion of the substrate to both products was observed but at significantly lower concentrations. The maximum concentration of isocarthamidin was $21.7 \mathrm{mg} / \mathrm{l}$ and carthamidin $21.5 \mathrm{mg} / \mathrm{l}$, with the initial concentration naringenin equal to $60 \mathrm{mg} / \mathrm{l}$. Another major advantage of our method is the short reaction time.

The optimal time of cultivation and biotransformation using A. niger was 3-4 days, whereas a 24-h-old culture of $R$. marina performed the reaction in $12 \mathrm{~h}$.

Moreover, biotransformations by yeasts are generally simpler and more convenient compared to molds.

The antioxidant activity was checked for the mixture of 12-h biotransformation extract and for the mixture of carthamidin and isocarthamidin (1:8) obtained after the purification of this extract. The 2,2'-diphenyl-1-picrylhydrazyl (DPPH) radical scavenging method was applied, using commercial naringenin as a control. The $\mathrm{IC}_{50}$ values were found as follows: $14.3 \mathrm{mg} / \mathrm{l}$ for the 12-h biotransformation mixture extract, $4.0 \mathrm{mg} / \mathrm{l}$ for purified hydroxylated products and $50.1 \mathrm{mg} / \mathrm{l}$ for naringenin. It was demonstrated that the mixture of carthamidin and isocarthamidin exhibited 12.5-fold higher DPPH scavenging activity than the substrate - naringenin.

\section{Conclusions}

On the basis of our results, we can conclude that biotransformation potential of Rhodotorula marina can be used in a new industrial approach for improvement of flavanone antioxidant properties. We are currently working on the use of cheap components of the cultivation medium for biotransformation involving $R$. marina.

Open Access This article is distributed under the terms of the Creative Commons Attribution License which permits any use, distribution, and reproduction in any medium, provided the original author(s) and the source are credited.

\section{References}

1. Fowler, Z. L., \& Koffas, M. A. G. (2009). Applied Microbiology and Biotechnology, 83, 799-808.

2. van Acker, F. A., Schouten, O., Haenen, G. R., van der Vijgh, W. J., \& Bast, A. (2000). FEBS Letters, 473, $145-148$.

3. Fang, F., Tang, Y., Gao, Z., \& Xu, Q. (2010). Biochemical and Biophysical Research Communications, 397, 163-169.

4. Cushnie, T. P. T., \& Lamb, A. J. (2005). International Journal of Antimicrobial Agents, 26, 343356.

5. Mandalari, G., Bennett, R. N., Bisignano, G., Trombetta, D., Saija, A., Faulds, C. B., Gasson, M. J., \& Narbad, A. J. (2007). Applied Microbiology, 103, 2056-2064.

6. Zandi, K., Teoh, B.-T., Sam, S.-S., Wong, P.-F., Mustafa, M. R., \& AbuBakar, S. (2011). Journal of Medicinal Plants Research, 5, 5534-5539. 
7. Choi, J. S., Park, K. Y., Moon, S. H., Rhee, S. H., \& Young, H. S. (1994). Archives of Pharmacal Research, 17, 71-75.

8. Liu, L. L., Xu, D.-M. D. M., \& Cheng, Y.-Y. Y. Y. (2008). Journal of Agricultural and Food Chemistry, 56, 824-829.

9. Wilcox, L. J., Borradaile, N. M., \& Huff, M. W. (1999). Cardiovascular Drug Reviews, 17, 160-178.

10. Lee, M. H., Yoon, S., \& Moon, J. O. (2004). Biological and Pharmaceutical Bulletin, 27, 72-76.

11. Renugadevi, J., \& Prabu, S. M. (2010). Experimental and Toxicologic Pathology, 62, 171-181.

12. Badary, O. A., Abdel-Maksoud, S., Ahmed, W. A., \& Owieda, G. H. (2005). Life Sciences, 76, 2125-2135.

13. Guthrie, N., \& Carroll, K. K. (1998). Advances in Experimental Medicine and Biology, 439, 227-236.

14. Frydoonfar, H. R., McGrath, D. R., \& Spigelman, A. D. (2003). Colorectal Disease, 5, 149-152.

15. Borradaile, N. M., de Dreu, L. E., \& Huff, M. W. (2003). Diabetes, 52, 2554-2561.

16. Mulvihill, E. E., Allister, E. M., Sutherland, B. G., Telford, D. E., Sawyez, C. G., Edwards, J. Y., Markle, J. M., Hegele, R. A., \& Huff, M. W. (2009). Diabetes, 58, 2198-2210.

17. Choi, J. S., Yokozawa, T., \& Oura, H. (1991). Planta Medica, 57, 208-211.

18. Ortiz-Andrade, R. R., Sanchez-Salgado, J. C., Navarrete-Vazquez, G., Webster, S. P., Binnie, M., GarciaJimenez, S., Leon-Rivera, I., Cigarroa-Vazquez, P., Villalobos- Molina, R., \& Estrada-Soto, S. (2008). Diabetes, Obesity \& Metabolism, 10, 1097-1104.

19. Kannappan, S., \& Anuradha, C. V. (2010). European Journal of Nutrition, 49, 101-109.

20. Lee, S., Lee, C.-H., Moon, S.-S., Kim, E., Kim, C.-T., Kim, B.-H., Boka, S.-H., \& Jeong, T.-S. (2003). Bioorganic and Medicinal Chemistry Letters, 13, 3901-3903.

21. Park, J.-H., Lee, J.-W., Paik, H.-D., Cho, S. G., Nah, S.-Y., Park, Y.-S., \& Han, Y. S. (2010). Food Science and Biotechnology, 19, 717-724.

22. Shimoda, K., Kubota, N., Taniuchi, K., Sato, D., Nakajima, N., Hamada, H., \& Hamada, H. (2010). Phytochemistry, 71, 201-205.

23. Kim, D. H., Kim, B.-G., Lee, Y., Ryu, J. Y., Lim, Y., Hur, H.-G., \& Ahn, J.-H. (2005). Journal of Biotechnology, 119, 155-162.

24. Chebil, L., Anthoni, J., Humeau, C., Gerardin, C., Engasser, J.-M., \& Ghoul, M. (2007). Journal of Agricultural and Food Chemistry, 55, 9496-9502.

25. Yaipakdee, P., \& Robertson, L. W. (2001). Phytochemistry, 57, 341-347.

26. Ibrahim, A.-R. S. (2000). Phytochemistry, 53, 209-212.

27. Ibrahim, A.-R. S., Galal, A. M., Ahmed, M. S., \& Mossa, G. S. (2003). Chemical and Pharmaceutical Bulletin, 51, 203-206.

28. Prasetyo, E. N., Nyanhongo, G. S., \& Guebitz, G. M. (2011). Process Biochemistry, 46, 1019-1024.

29. Miyake, Y., Minato, K., Fukumoto, S., Yamamoto, K., Oya-Ito, T., Kawakishi, S., et al. (2003). Bioscience, Biotechnology, and Biochemistry, 67, 1443-1450.

30. Ye, H., Xu, H., Yu, C., Dai, Y., Liu, G., Xu, W., \& Yuan, S. (2009). Enzyme and Microbial Technology, 45, $282-287$.

31. Madej, A., Popłoński, J., \& Huszcza, E. (2012). Przemyst Chemiczny, 91(5), 856-859.

32. Xu, J., Yang, L., Zhao, S.-J., Wang, Z.-T., \& Hu, Z.-B. (2012). World Journal of Microbiology and Biotechnology, 28, 1803-1806.

33. Kim, G.-N., Shin, J.-G., \& Jang, H.-D. (2009). Food Chemistry, 117, 35-41.

34. Satoru, K., Tsumoru, W., Yoshiharu, I., Atsuko E., Antidiabetic agent, JP 2008133192 A.

35. Chang, T. S. (2009). International Journal of Molecular Sciences, 10, 2440-2475.

36. Solomon, E. I., Chen, P., Metz, M., Lee, S., \& Palmer, A. E. (2001). Angew. Chem. - Int Ed., 40, 4570-4590.

37. Seo, S. Y., Sharma, V., \& Sharma, N. J. (2003). Journal of Agricultural and Food Chemistry, 51, $2837-2853$.

38. Rescigno, A., Sollai, F., Pisu, B., Rinaldi, A., \& Sanjust, E. (2002). J. Enz. Inhib. Med. Chem., 17, $207-218$.

39. Mosher, A. M., Pathak, M. A., \& Fitzpatrick, T. B. (1983). In T. B. Fitzpatrick, A. Z. Eisen, K. Wolff, I. M. Freedberg, \& K. F. Austern (Eds.), Dermatology in General Medicine (pp. 205-225). New York: Mc-GrawHill.

40. Xu, Y., Stokes, A. H., Freeman, W. M., Kumer, S. C., Vogt, B. A., \& Vrana, K. E. (1997). Molecular Brain Research, 45, 159-162.

41. Asanuma, M., Miyazaki, I., \& Ogawa, N. (2003). Neurotoxicity Research, 5, 165-176.

42. Kima, Y. J., \& Uyamab, H. (2005). Cellular and Molecular Life Sciences, 62, 1707-1723.

43. Chang, T.-S., Lin, M.-Y., \& Lin, H.-J. (2010). Journal of Cosmetic Science, 61, 205-210.

44. Sugumaran, M. (1991). FEBS Letters, 293, 4-10.

45. Goh, D., Lee, Y. H., \& Ong, E. S. (2005). Journal of Agricultural and Food Chemistry, 53, 8197-8204.

46. Horvath, C. R., Martos, P. A., \& Saxena, P. K. (2005). Journal of Chromatography A, 1062, $199-207$.

47. Werawattanachai, N., \& Kaewamatawong, R. (2010). Biochemical Systematics and Ecology, 38, 836-838.

48. Jin, Y., Xiao, Y., Zhang, F., Xue, X., Xu, Q., \& Liang, X. (2008). J. Pharmaceut. Biomed., 46, 418-430.

49. Sharma, O. P., \& Bhat, T. K. (2009). Food Chemistry, 113, 1202-1205. 